\title{
Correction to: Performance Evaluation of Moment-Resisting Steel Frame Buildings Under Seismic and Blast-Induced Vibrations
}

\author{
Muhammed Zain Kangda ${ }^{1}$. Sachin Bakre ${ }^{2}$
}

Published online: 28 January 2019

(c) KrishteleMaging Solutions Private Limited 2019

\section{Correction to: \\ Journal of Vibration Engineering \& Technologies https://doi.org/10.1007/s42417-018-0027-2}

The original version of Fig. 16 unfortunately contained mistakes. The corrected Fig. 16 is given below.

The original article can be found online at https://doi.org/10.1007/ s42417-018-0027-2.

Muhammed Zain Kangda zainkangda@gmail.com

1 Applied Mechanics Department, Visvesvaraya National Institute of Technology, Nagpur, India

2 Department of Applied Mechanics, Visvesvaraya National Institute of Technology, Nagpur, India 

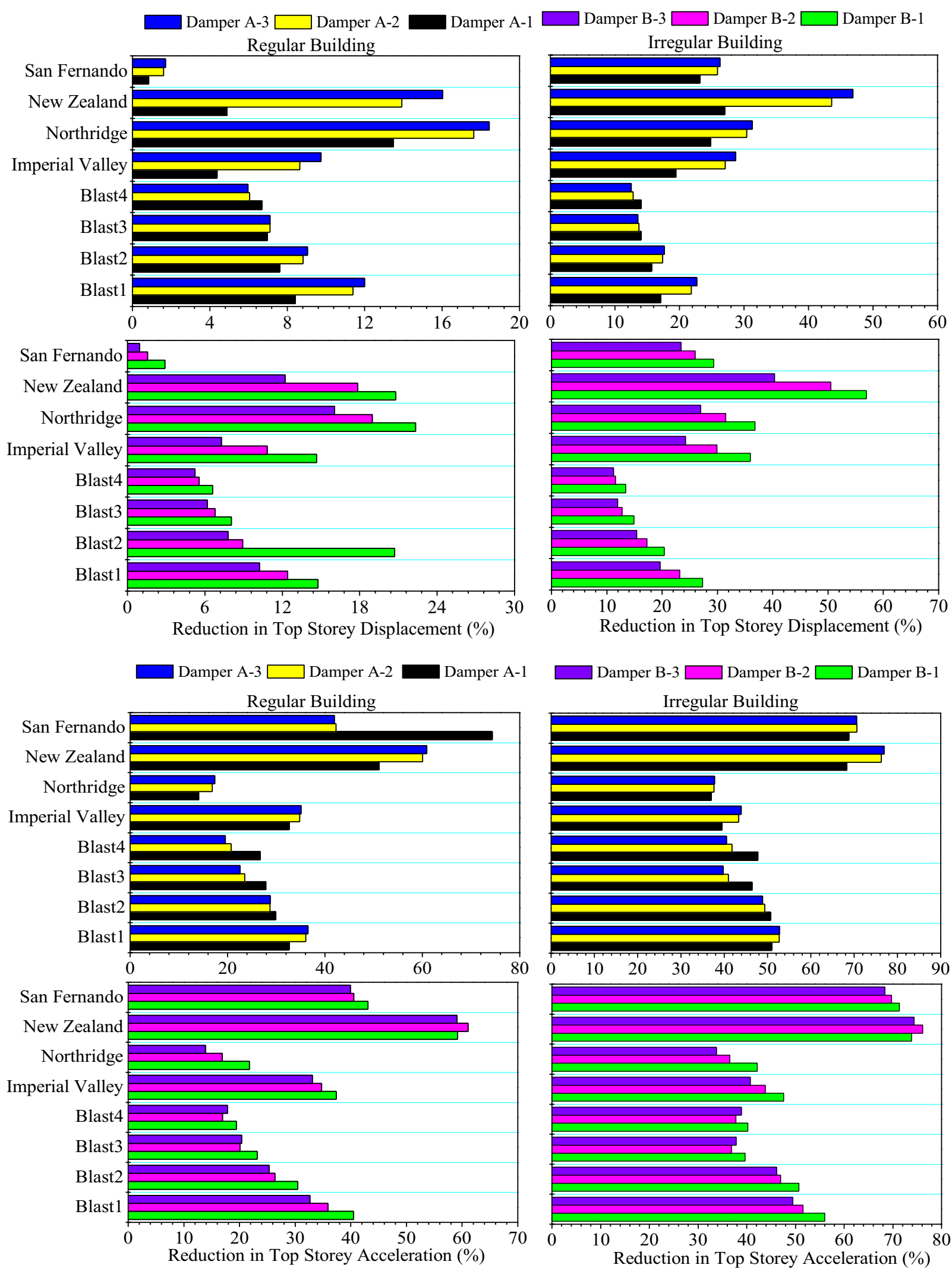

Fig. 16 Performance of steel buildings equipped with viscous dampers under dynamic loading 
Publisher's Note Springer Nature remains neutral with regard to jurisdictional claims in published maps and institutional affiliations. 